\title{
New nomenclature combinations for vascular plant taxa
}

\section{IVAN IVANOVYCH MOYSIYENKO}

МойсІєНКО I.I., 2010: Нові номенклатурні комбінації таксонів судинних рослин. Чорноморськ. ботан. ж., т. 6, № 1: 102-103.

В статті пропонується ряд нових номенклатурних комбінацій в родах Achillea L., Buglossoides Moench, Lotus L., Pseudolisymachion Opiz, Pulsatilla Mill. та Ranunculus L.

Ключові слова: номенклатурні комбінащії, судинні рослини, флора Причорномор'я.

MOYSIYENKO I.I., 2010: New nomenclature combinations for vascular plant taxa. Chornomorsk. bot. z., vol. 6, N 1: 102-103.

Some new nomenclature combinations in Achillea L., Buglossoides Moench, Lotus L., Pseudolisymachion Opiz, Pulsatilla Mill. та Ranunculus L. are proposed.

Key words: nomenclature combinations, vascular plants, northern Black Sea Coast.

МойсиЕнкО И.И., 2010: Новые номенклатурные комбинации таксонов сосудистых растений. Черноморск. ботан. ж., т. 6, № 1: 102-103.

В статье предлагается ряд новых номенклатурных комбинаций в родах Achillea L., Buglossoides Moench, Lotus L., Pseudolisymachion Opiz, Pulsatilla Mill. тa Ranunculus L.

Ключевые слова: номенклатурные комбиначии, сосудистые растения, флора Причерноморья

Carrying out flora inventory in the South- and Middlesteppe landscapes of northern Black Sea Coast region, we have studied thoroughly morphology of many species in their native occurrences so a new nomenclature combinations are proposed for some of them now. For five taxa with transition characters (incl. those close to type species) we propose subspecies rank. Also two combinations are proposed at species level because of separation of genus Pseudolisymachion Opiz from Veronica L. [ЦВЕЛЕВ, 2000, FLORA OF CHINA, 1998, TRÁVNÍČEK at al., 2005] and, in other case, in connection with repeated inclusion of genus Ficaria Guett. to Ranunculus L. [HöRANDL et al., 2005].

\section{Combinations at the subspecies rank:}

ACHILlea setacea Waldst. et Kit. subsp. stepposa (Klokov et Krytska) Moysiyenko comb. nova. - Basionym: Achillea stepposa Klokov et Krytska, 1984, Тысячелистники: 240-241.

BuglossoIDES arvensis (L.) Johnst. subsp. czernjajevii (Klokov) Moysiyenko comb. nova. - Basionym: Lithospermum czernjajevii Klokov, 1936, Тр. Ін. ботан. Харк. унів. 1: 75 .

LotUS corniculatus L. subsp. elisabethae (Opperm. ex Wissjul.) Moysiyenko comb. nova. Basionym: Lotus elisabethae Opperm. ex Wissjul., 1954, Фл. УРСР, 6.

Pseudolysimachion spicatum (L.) Opiz subsp. barrelieri (H.Schott ex Roem. \& Schult.) Moysiyenko comb. nova. - Basionym: Veronica barrellieri Schott, 1817, in Roem. a Schult., Syst. Veg. 1: 94.

\footnotetext{
(c) Мойсієнко I.I.

Чорноморськ. бот. ж., Т. 6, № 1: 102-103.
} 
Pulsatilla pratensis Mill. subsp. ucranica (Ugr.) Moysiyenko comb. nova. - Basionym: Anemone pulsatilla L. var. ucranica Ugr., 1911, Труды исп. прир. Харьк. Унив. 44: 312., tab. 4.

\section{Combinations at the species rank:}

RANUNCUluS stepporum (P.Smirn.) Moysiyenko comb. nova. - Basionym: Ficaria stepporum P. Smirn., 1958, Тр. Приокско-Терр. Запов. 2: 142.

PSEUdOLYSIMACHION pseudoorchideum (Pacz.) Moysiyenko comb. nova. - Basionym: Veronica spicata L. var. pseudoorchidea Pacz., 1910, Зап. Новорос. Общ. Естествоиспыт. XXXIX: 143.

\section{References}

ЦвеЛЕВ Н.Н. Определитель сосудистых растений северо-западной России (Ленингадская, Псковская и Новгородская области). - СПб.: Издательство СПХФА, 2000. - 781 с.

Flora of ChinA. (Scrophulariaceae through Gesneriaceae). / Eds. Wu Z. Y., Raven P. H. - St. Louis: Science Press, Beijing, and Missouri Botanical Garden Press, 1998. - Vol. 18. - 450 pp.

Hörandl E., Paun O., Johansson J.T., Lehnebach C., Armstrong T., Chen L., Lockhart P. Phylogenetic relationships and evolutionary traits in Ranunculus s.l. (Ranunculaceae) inferred from ITS sequence analysis // Mol. Phylogenet Evol. - 2005. - 36 (2). - P. 27-305.

TrÁvníčeK B., LysÁK A. M., Č́́HALÍkOvÁ J., DoležEl J. Karyo-taxonomic study of the genus Pseudolysimachion (Scrophulariaceae ) in the Czech Republic and Slovakia // Folia Geobotanica. 2004. - V. 39, N 2. - P. 173-203.

Рекомендує до друку

Отримано 12.07.2010 р.

\section{А.В. Сна}

Aдpeca автора:

I.I. Мойсієнко

Херсонський державний університет

Вул. 40 років Жовтня, 27

73000 Херсон,

Украӥна

e-mail: Vanvan@ksu.ks.ua
Author's address:

Ivan Moysiyenko,

Kherson State University,

Str. 40 let Oktriabrya 27

73000 Kherson,

Ukraine

e-mail:Vanvan@ksu.ks.ua 